Supplement of Atmos. Chem. Phys. Discuss., 14, 22437-22475, 2014

http://www.atmos-chem-phys-discuss.net/14/22437/2014/

doi:10.5194/acpd-14-22437-2014-supplement

(C) Author(s) 2014. CC Attribution 3.0 License.

(c) (i)

\title{
Aging of secondary organic aerosol generated from the ozonolysis of $\alpha$-pinene: effects of ozone, light and temperature
}

\author{
C. Denjean et al.
}

Correspondence to: C. Denjean (denjean@ tropos.de) 


\section{Supplementary material}

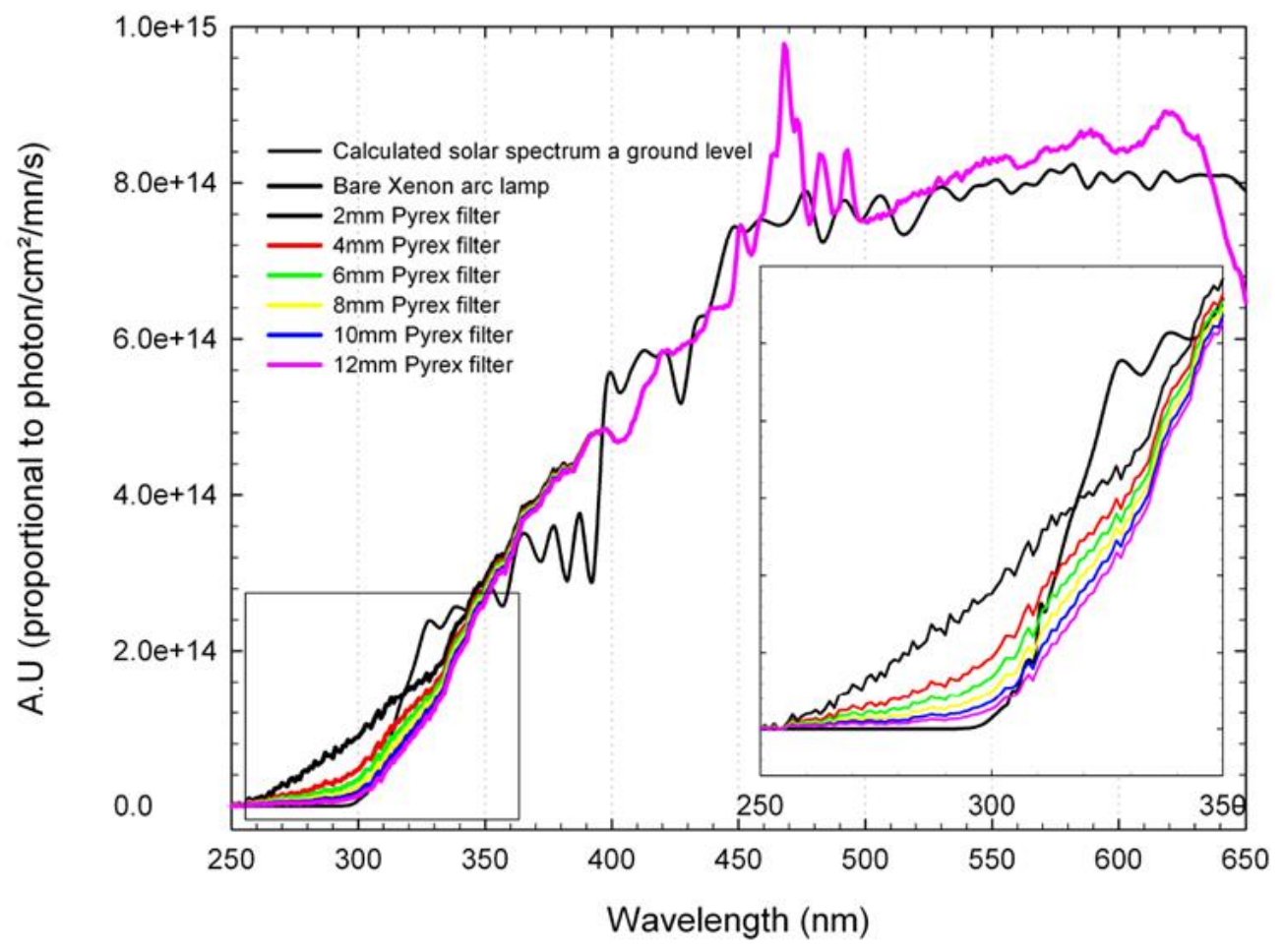

Figure S1. Comparison of irradiation spectra. The black curve is solar spectrum calculated from TUV NCAR, 12:00 solar time, Equator, 21 June. The thick color curves are spectra of xenon filtered by different thicknesses of Pyrex films (the solar spectrum is scaled to the lamps spectra to facilitate comparison of their shapes). A Pyrex film of $8 \mathrm{~mm}$ was used in this study. 